\title{
Flexible Learning Design and Implementation Based on Big Data
}

\author{
K.Naresh ${ }^{1}$ | P.Baby Maruthi ${ }^{2}$ | P.Leela ${ }^{3}$ \\ ${ }^{1}$ Information Technology, Sri Venkateswara College Of Engineering, Tirupati, Andhrapradhesh, India \\ ${ }^{2}$ Master of Computer Applications, Sri Venkateswara College Of Engineering, Tirupati, Andhrapradhesh, India \\ ${ }^{3}$ Information Technology, Sri Venkateswara College Of Engineering, Tirupati, Andhrapradhesh, India
}

To Cite this Article

K.Naresh, P.Baby Maruthi and P.Leela, "Flexible Learning Design and Implementation Based on Big Data", International Journal for Modern Trends in Science and Technology, 6(8S): 01-05, 2020.

\section{Article Info}

Received on 16-July-2020, Revised on 15-August-2020, Accepted on 25-August-2020, Published on 28-August-2020.

\section{ABSTRACT}

The traditional face-to-face schooling model can now not meet the needs of in addition education outstanding talents. Only through the huge information studying evaluation version, we can discover deeply and take a look at the learner's studying method, find out the getting to know rules, and then provide them in keeping with the characteristics and wishes of each pupil; personalised adaptive gaining knowledge of and learning methods to give complete play to the ability of students. This research starts from the connotation and alertness of huge facts, and the comprehensiveness of the statistics and the capability "huge value". Based on massive facts analysis, a personalized adaptive online mastering analysis model is built from 4 dimensions: Data and Environment (Who), How and Target (Why). Taking C-language programming as an example, this paper analyzes the shape of learning technique based on large facts and adaptive getting to know, the visualization of getting to know technique and the empirical impact of getting to know. The research results display the information analysis of college students' mastering conduct and knowledge mastery. It can suggest a affordable getting to know course and appropriate gaining knowledge of resources, and can provide well timed and correct comments on the learning effect of students, and offer customized carrier intervention, which is conducive to the merchandising of teaching and learning.

KEYWORDS: Huge records; customized adaptive studying, mastering analysis; visualization

\section{INTRODUCTION}

With the slow development of the schooling device, the cause of teaching and educating humans has turn out to be clean gradually, however there also are many problems. For example, instructors handiest follow their own thoughts to educate and complete the corresponding coaching tasks, however they neglect the scholars' ability to accept; the incentive mechanism to acquire interplay influences the scholars' self-awareness and enthusiasm [1]. It results in the gradual burying of students' thinking capacity and the non-stop discount of their ability to collect expertise and innovation. The lack of actual attention to the individual variations and exceptional desires of students is opposite to the educational idea of "coaching college students in line with their aptitudes" from ancient times to the present, that is, personalised schooling. In view of this, experts and scholars in the schooling quarter and instructors inside the school are striving to locate affordable and effective solutions. However, because of the lack of ability to absolutely hold close the getting to know degree of each scholar and the lack of ability to tune the real learning state of affairs of the students in time, they can't be dynamically adjusted pupil learning strategies. However, with the rapid development of the mobile 
Internet, educational statistics has come to be increasingly popular, and the way of understanding dissemination and get right of entry to has undergone fundamental changes [2]. The rise of online mastering has been recognized progressively by instructors, college students, and parents, not simplest because it can achieve lifelong, but also it enables college students to draw a three-dimensional gaining knowledge of photograph from the time, space and content dimensions to obtain rich and high-best learning resources. More importantly, it's miles viable to deeply explore learner facts through online getting to know, which can sell the dynamic dating between teaching and gaining knowledge of between instructors and college students. In particular, due to the adulthood of present day technologies such as "big information" and "studying evaluation", more personalized adaptive getting to know affords protection.

\section{THE MEANING AND APPLICATION OF BIG DATA}

\section{A. Big Data Adaptive Learning Concept}

Data is the carrier of information and the supply of understanding. Big statistics adaptive learning refers to the concern area information, the studies results in various fields, the lecture notes and coaching revel in of instructors, the classic teaching cases, the take a look at questions and answers, and the readers' reading enjoy[3]. By categorizing and collecting, college students can learn expertise factors through online gaining knowledge of or offline downloading, in order to carry out customized gaining knowledge of, and additionally talk and discuss with instructors online. As Bill Gates once stated at an academic convention in Austin, Texas, "The use of information analytics in schooling massive information can improve student achievement, save the US public school system, and broadeneducational technology as records."

\section{B. The Value and Application of Big Data}

At the macro degree, huge facts is defined as a massive, high-growth, and diversified data asset that calls for a new processing version to have extra decision-making power, insight and procedure optimization capabilities. It has 4V traits: Volume, Velocity, Variety, Veracity, and some scholars believe that different $\mathrm{V}$ need to be added: Value and Visualization. Data expert $\mathrm{Tu}$ Zipei said: "Big statistics might be our next 'microscope' and 'dashboard' to take a look at and monitor human social behavior." To recognize the connotation of huge data from a micro perspective, the "massive" of big records is not centered on the "large capacity" of its appearance, but on the comprehensiveness of the data and the ability "large value". Big information

evaluation in training need to measure the microscopic performance within the gaining knowledge of system with new questioning and technical cognizance, and mine valuable records information from a couple of dimensions, along with learning attitude, intelligence degree, domain competence, and interplay, and present them in a visual way. On the one hand, recognise coaching intervention, promote coaching and mastering, and alternatively domesticate individualized improvement. Without the retention and deep excavation of facts, schooling informatization can only be inside the form, and every revolution in era has revolutionized an era of education. The question is how to assemble a scientific and rational evaluation version, and believe and cling to the output of the evaluation version. Correct the analysis version to acquire comprehensive monitoring and studying of pupil characteristics, behaviors and processes, analyze college students' questioning behavior and ways of questioning, behavior targeted coaching, and examine college students greater accurately, improve students' mastering satisfactory and gaining knowledge of efficiency. Therefore, this take a look at will consciousness on one of the important additives of the teaching device - getting to know effectiveness evaluation, based totally on huge records and learning analysis era to discover personalized adaptive online studying evaluation version and its basic

\section{BUILD A PERSONALIZED ADAPTIVE ONLINE LEARNING ANALYSIS MODEL BASED ON BIG DATA}

Learner adaptive learning shape and statistics flow, understand facts analysis explicit records and implicit information, construct learner feature version, and then provide adaptive studying direction and object, etc., and teachers can also learn in line with beginners The getting to know conduct and needs, the implementation of personalized steering, the whole manner is especially the interaction between freshmen and systems, and teachers, but the interaction between rookies and rookies is not reflected, which is not conducive to inexperienced persons to find out new know-how [5]. Therefore, the personalised adaptive gaining knowledge of machine based totally on 
large statistics additionally needs to don't forget the usage of collaborative filtering generation to obtain the getting to know records of the newbies who have the identical or similar hobby preference characteristics to the learner. This examine affords a customized adaptive gaining knowledge of shape primarily based on big information, as proven in The customized adaptive studying structure primarily based on large facts consists of seven hyperlinks, which absolutely explains the approaches and strategies that rookies can attain learning. Through the four hyperlinks (1), (4), (5) and (6), the learner can comprehend self-organizing getting to know in keeping with the visual statistics in the dashboard (along with learner traits, getting to know outcomes, studying needs, etc.), formulate and execute Learning plans, self-selected studying

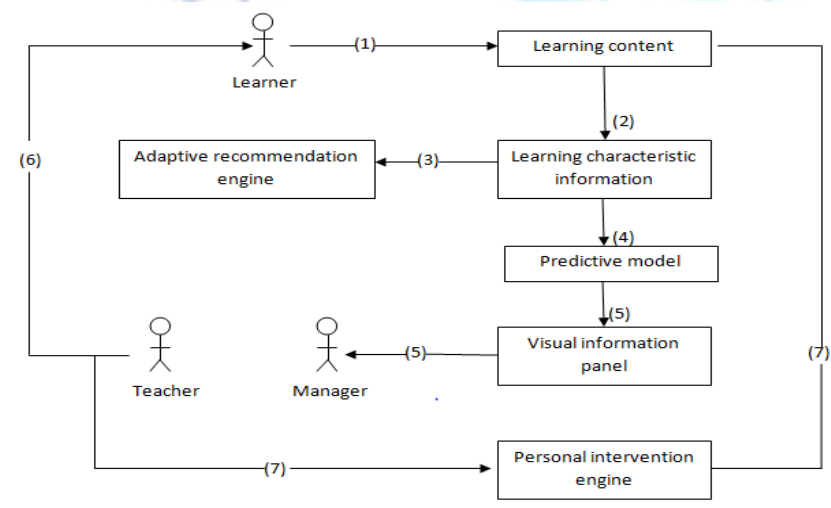

Figure-1: Personalized adaptive learning structure based on big data.

strategies, studying resources, and self-assessment of mastering can help to improve college students' self-consciousness and initiative. The gadget can adopt Bayesian through three hyperlinks: (1), (2) and (3). Network, collaborative filtering recommendation era, project reflection theory, Felder-Silverman mastering fashion version and Hofstein tradition model [6]. Such as learning fashion, interest preference, knowledge degree, getting to know culture and other learner traits, adaptability to give personalised, visual getting to know paths, getting to know resources, peer facts, tools, etc., help to increase college students' self-efficacy; through the 5 hyperlinks of (1), (2), (4), (5) and (7), instructors and managers can be realized. Visualize user facts within the information panel, adjust coaching strategies, implement customized steering and coaching intervention, help to grasp inexperienced persons' getting to know rules, optimize gaining knowledge of technique, improve gaining knowledge of effects, and beautify coaching first-rate.

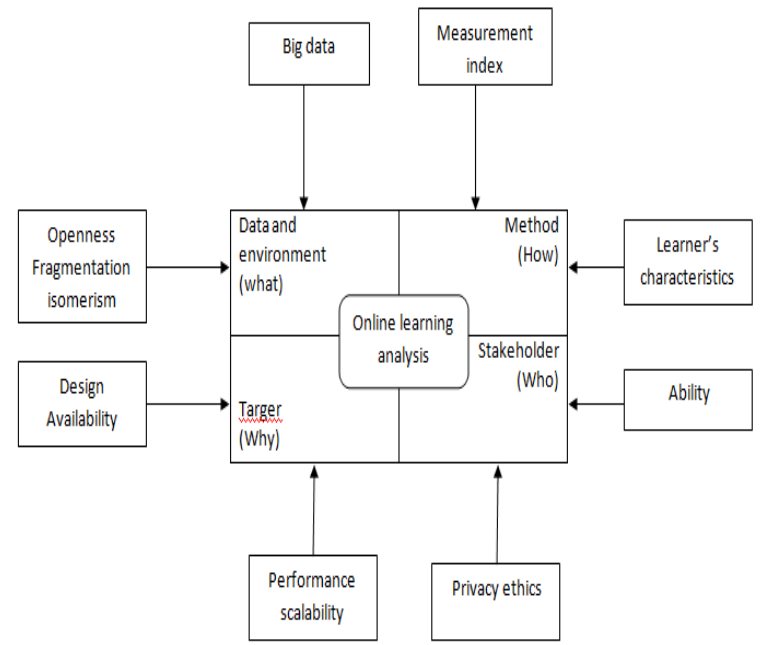

Figure-2: Personalized adaptive online learning analysis model.

Personalized adaptive online getting to know analysis version production from the structure of personalised adaptive gaining knowledge of process primarily based on massive facts, we can not handiest consider the individualized characteristics of students, but also consider the approach of mining treasured personalised studying records from big records [7]. Therefore, this study combines the adaptive getting to know gadget developed with the aid of the project, based on the theory of personalized self-learning, customized adaptive recommendation, persona psychology and laptop science, from facts and environment (What), associated stakeholders (Who), a self-adaptive online getting to know analysis version is constructed in four dimensions, as shown in Figure 2.

\section{AN EXAMPLE OF PERSONALIZED ADAPTIVE ONLINE LEARNING ANALYSIS MODEL: "C LANGUAGE PROGRAMMING" COURSE LEARNING}

\section{A. Personalized Adaptive Learning Supported by} Visualization and Big Data Learning Analysis

(1) Knowledge structure visualization in keeping with the concept of unicomism, the chapter studying content material is presented to college students in the shape of information map visualization, which realizes the effective employer of information and may clarify the connection between know how on the premise of adapting to the learner's visual processing habits [8]. The logical relationship reduces the cognitive load of rookies, promotes meaningful mastering of 
beginners, long-time period memory, and energetic construction and migration of know-how. At the same time, the visualization of know-how shape also can enable beginners to increase cognitive needs along with exploration, curiosity, and understanding, so that their hobbies and interest are concentrated, and the conscious tendency to solve problems is generated, thereby producing certain cognitive wishes, inspiring curiosity, and initiative. The desire to learn. As proven in Figure 3 , the $\mathrm{C}$ language programming route knowledge structure map.

Figure-3:

When getting to know a certain know-how point, the learner can choose from the shape map, or click the selection from the expertise tree at the left aspect of the adaptive mastering machine. Good studying resource sequences and learning instance sequences (expressed in exceptional importance ranges, issue factors, semantic density, media types), gaining knowledge of pastime sequences (expressed in different gaining knowledge of styles) and exercises and exams suitable for novices (in line with Bloom's six cognitive classifications to fulfill the extent of wondering at different levels of cognition), adaptive studying and self-enterprise for beginners Learn. In addition, at the right aspect of the gadget, the expertise of the front, the latter and the associated understanding of the getting to know knowledge points also are presented within the form of expertise maps, forming a correlation show between the new know-how and the original expertise, which is beneficial to

construct learner's know-how mastering.

User-precise adaptive gaining knowledge of system based on massive records analysis Visual training measurement is not handiest for outcomes, however additionally have to recognition at the 5 steps of "coaching", "learning", "practicing", "measuring" and "answering", which completed. This study makes use of big statistics studying analysis to instantly quantify the learning method and visualize it, so that the wisdom inside the facts can flow to rookies, peers, and teachers in an intuitive way, so that it could see the dynamic modifications of studying cognition greater clearly. To understand their latest gaining knowledge of situation, to recognize their own distance from the very last gaining knowledge of objectives, to stimulate the intrinsic motivation of learners to learn, to understand themselves, to broaden themselves, to devise themselves, to improve beginners' metacognitive capacity and self-efficacy[9].

\section{B. Empirical Research on Personalized Adaptive Learning Based on Big Data Analysis}

With the guide of big statistics evaluation, it is able to comprehensively record, music and master the one-of-a-kind studying characteristics, learning needs, gaining knowledge of foundation and mastering conduct of novices, and for extraordinary types. The learner creates a personalised mastering path, dynamically adapts the content, time, method and other elements of the coaching to implement interventional teaching, which can beautify the gaining knowledge of efficiency of the college students. In order to verify this factor of view, and additionally to verify the effectiveness of the proposed large statistics-based totally customized adaptive online gaining knowledge of evaluation model, this test is based totally at the "service" adaptive mastering system SOALS (Service-Oriented) developed by means of the mission team. Adaptive Learning System) is a studies platform, and 60 college students of 2018 training era majors are decided on as subjects to look at $\mathrm{C}$ language programming. They are randomly divided into groups, experimental institution (adaptive gaining knowledge of and control organization ( Non-adaptive studying), 30 human beings each, there was no great difference in cognitive capability between the 2 groups. At the identical time, in step with the pre-test effects, the additives had been terrible college students (0-4 points) and exceptional students (5-9 points). During the -month examine, all students inside the experimental institution and

the manipulate group performed After the knowledge factor is measured, the results of some information analysis are shown in the following table.

\begin{tabular}{|l|l|l|l|l|}
\hline & \multicolumn{2}{|l|}{ Control Group } & Test Group \\
\hline & $\begin{array}{l}\text { Poor } \\
\text { Students }\end{array}$ & $\begin{array}{l}\text { Excellent } \\
\text { Students }\end{array}$ & $\begin{array}{l}\text { Poor } \\
\text { Students }\end{array}$ & $\begin{array}{l}\text { Excellent } \\
\text { Students }\end{array}$ \\
\hline Front Side & 3.8 & 5.8 & 3.8 & 5.9 \\
\hline Back Side & 5.9 & 7.0 & 7.3 & 7.1 \\
\hline $\begin{array}{l}\text { Study Time } \\
\text { Constrints }\end{array}$ & 2205 & 1816 & 1623 & 1449 \\
\hline $\begin{array}{l}\text { Discard } \\
\text { The No of } \\
\text { Questions }\end{array}$ & 48 & 30 & 19 & 10 \\
\hline $\begin{array}{l}\text { Try to solv } \\
\text { the number } \\
\text { of times }\end{array}$ & 70 & 90 & 33 & 25 \\
\hline
\end{tabular}

Table:1Data Analysis Learning Results Table

It may be visible from the statistics in desk 1 that the improvement impact of the gaining knowledge 
of overall performance within the experimental group is the most obvious, and the rating is progressed from the pre-test 1853.8 to the post-check 7.3. In comparison, the improvement of the extraordinary college students' academic performance is not obvious, and the experimental group and the manage organization are not obvious. There is no massive difference within the academic overall performance of exceptional college students. The reason for the evaluation is that poor students are all learning in line with the gaining knowledge of path of the adaptive device and the studying materials of appropriate problem. The notable students have strong autonomy and do no longer fully believe inside the system recommendation. It can be visible that the personalized adaptive studying evaluation model primarily based on huge facts is extra powerful for poor existence intervention guidance. In addition, the gaining knowledge of time of the facts evaluation inside the desk, the variety of deserted questions and the variety of tries to resolve the problem, the

experimental institution students are much less than the control organization students. The information analysis of conduct and knowledge factors can extra correctly judge the cognitive potential of students, and then the suitable issue of personalized adaptive promotion is in keeping with the cognitive stage of students. So most questions may be accurately answered by college students with out giving up, or try to solve it more than one times.

\section{v. CONCLUSION}

The statistics created by each learner is part of "large facts," and every learner is a manufacturer and consumer of massive information. With the assist of large statistics analysis, the individualized push of mastering sources and the evaluation of mastering exceptional will have possible solutions [10]. The personalized adaptive online gaining knowledge of evaluation model based on massive statistics proposed in this paper has basically realized the deep mining mastering conduct pattern, revealing the hidden relationships, patterns and traits between data, know-how the trajectory of learners' growth, and expertise learners' getting to know, which it helps to grasp the studying guidelines of learners helps a extra comprehensive assessment of students and individualized intervention guidance, and certainly achieves the motive of "assessment for pupil development", optimizes the mastering process, and is conducive to the improvement of learning capability and hobby in studying. In short, powerful customized studying wishes to be primarily based on big records to record learner getting to know process, analyze learners' thinking habits, and combine appropriate studying scenarios to push appropriate learning assets. It may be seen that large information is the foundation of education destiny, personalized adaptive gaining knowledge of. Let coaching return to the essence, the maximum human-oriented learning, belongs to the destiny instructional ecosystem.

\section{REFERENCES}

[1] Huang Y. Pure design and implementation of RBAC system based onSaaS model [D].Northeast Normal University, 2013.

[2] Liu Kaihua, Li Xiong. Cloud computing security model and strategyanalysis $[\mathrm{J}]$. Computer Knowledge and Technology, 2011,7 (08): 1750-1751.

[3] Zhou Wenbin. Research on Information Security Based on Cloud SaaS Model [D]. Liaoning Technical University, 2014.

[4] Wang Q, Wang C, Li J, Ren K, Lou W. Enabling public verifiability and data dynamics for storage security in cloud computing. In: Backes M, Ning P, eds. LNCS 5789. Heidelberg: Springer-Verlag, 2009. 355-370.

[5] Liu Yingjie, Wang Lunyan, Hu Fangyuan, Yuan Lu. Security AccessControl in SaaS Mode Based on Improved RBAC Model [J] .Modern Computer, 2017 (15): 81-84.

[6] YANG Li. Research on User Information Security in Cloud Computing Environment [J]. Taxpayer, 2017 (15): $65+67$.

[7] Feng Dengguo, Zhang Min, Zhang Yan, et al.Study on Cloud Computing Security $[\mathrm{J}]$.Journal of Software, 2011,22 (1): 71-83. 